\title{
Comparative Evaluation of Ozone Treatment in Critical Size Bone Defects Reconstructed with Alloplastic Bone Grafts
}

\author{
Nihat Laçin'1, Beyza Kaya², Engin Deveci³, Ela Tules Kadiroğlư4, Ayfer Aktaş³, Mustafa Yalçın", \\ Ersin Uysal 6
}

\begin{abstract}
${ }^{1}$ Department of Oral and Maxillofacial Surgery, Faculty of Dentistry, University of Katip Çelebi, İzmir, Turkey ${ }^{2}$ Department of Oral and Maxillofacial Surgery, Faculty of Dentistry, University of Dicle, Diyarbakır, Turkey ${ }^{3}$ Department of Histology and Embryology, Faculty of Medicine, University of Dicle, Diyarbakir, Turkey ${ }^{4}$ Department of Periodontology, Faculty of Dentistry, University of Dicle, Diyarbakır, Turkey ${ }^{5}$ Department of Oral and Maxillofacial Surgery, Faculty of Dentistry, University of Gaziantep, Gaziantep, Turkey ${ }^{6}$ Department of Statistic, Vocal Sch.Tech.Sci. Dicle University, Diyarbakır, Turkey

Email: engindeveci64@gmail.com
\end{abstract}

How to cite this paper: Laçin, N., Kaya, B., Deveci, E., Kadiroğlu, E.T., Aktaş, A., Yalçın, M. and Uysal, E. (2018) Comparative Evaluation of Ozone Treatment in Critical Size Bone Defects Reconstructed with Alloplastic Bone Grafts. International Journal of Clinical Medicine, 9, 566-579.

https://doi.org/10.4236/ijcm.2018.97048

Received: June 5, 2018

Accepted: July 17, 2018

Published: July 20, 2018

Copyright $\odot 2018$ by authors and Scientific Research Publishing Inc. This work is licensed under the Creative Commons Attribution International License (CC BY 4.0).

http://creativecommons.org/licenses/by/4.0/

\begin{abstract}
The purpose of this study was to investigate osteogenesis promoted by osteoconductive properties of bone grafting materials and the histopathological effects of ozone on osteogenesis. In total, 56 Winstar rats were equally divided into 4 groups. In control group, calvarial bone defect was created in 14 rats. For second group, $8 \mathrm{~mm}$ calvarial bone defect with ozone treatment was applied in 14 rats. For third group, an alloplastic bone graft was implanted on 8 $\mathrm{mm}$ calvarial bone defect. In fourth group, alloplastic bone graft was inserted in calvarial defect and ozone was treated additionally. Seven of the rats were sacrificed at the end of 4 th week and the remaining 7 were sacrificed at the end of 8th week of experiment. In the study, the periosteal flaps were removed with a thin periosteal elevator and averagely $0.8 \mathrm{~cm}$ diameter-circular full bone defect was created with a specially designed trephine drill. The bone from the calvarial region was fixed in $10 \%$ formalin solution. After decalcification, bones were taken for routine paraffin blocking. Sections were stained with Hematoxylin-Eosin and Masson Trichrome. Histopathological findings of 4 th and 8 th weeks rats showed that best result for new bone formation was observed in graft + ozone treatment. It is concluded that ozone treatment increases the hemostasis in graft region, induces angiogenesis, promotes cell proliferation by preventing infiltration, induces matrix formation by influencing osteoblastic activity and has a positive effect in osteogenesis.
\end{abstract}




\section{Keywords}

Calvarial Bone Graft, Ozone, Osteoblast Cells, Rat

\section{Introduction}

Fracture healing depends on many actors: Local factors such as the degree of trauma, the position of the wound edges relative to each other, the vascularization of the wound area, the type of bone, the degree of immobilization, the amount of local necrosis and soft tissue damage, the presence of infections and systemic diseases (i.e. age, diabetes, anemia, tuberculosis); hormones such as parathyroid, calcitonin, insulin, growth hormones; vitamins such as $\mathrm{A}, \mathrm{C}$ and $\mathrm{D}$ and general factors such as chondroitin sulphate and exercises [1] [2]. Cortical grafts provide a durable and rigid structure but they have no ability to increase osteogenesis. The primary advantage of cancellous bone and bone marrow is that they are able to significantly enhance osteogenesis. These abilities depend on the fact that they have viable cells that can transform into osteoblasts as well as those that induce osteogenesis. The only known disadvantage of these grafts is that they can't provide mechanical stability [3] [4].

Allografts are bone tissues obtained from genetically different individuals but sharing properties of same species with donor. Fresh frozen bone can be classified as frozen dried bone and demineralized bone matrix [5] [6]. Due to the limited availability of autografts, undesirable features of allografts and xenografts such as the risk of disease transfer, researchers have now been focused on synthetically graft materials which of them have been produced for use in bone defects. Since large numbers of those materials are produced, they should be studied well in researches. Alloplasts have become a necessary material in recent years for the repair of maxillofacial skeleton [7] [8].

Ozone is available in the stratosphere layer of earth at a concentration of 1 to $10 \mathrm{ppm}$ in the gas phase. The disinfection property of ozone is due to its strong oxidizing property. Not only do they kill viruses and bacteria, they can also oxidize all microorganisms and their toxins. Ozone can also effectively neutralize phenols, pesticides, detergents, chemical wastes, and aromatic compounds [9]. Ozone is widely used in stomatology as a disinfectant. Besides, it also can be used in wound healing after tooth extraction, the treatment of oral infections, cases of candidiasis or periodontitis, stomatitis, treatment of infected wounds in soft tissues, and oral cavity washing prior to surgery [10]. Ozone treatments have positive effects in studies of on wound healing, ischemic and infectious diseases. It is also effectively used in many infectious diseases from simple dental and oral infections to hepatitis [11]. Studies show that ozone treatment has benefited significantly in pit and fissure caries [12], non-cavitated occlusal caries [13], and root caries at the initial stage [12] [13] [14]. The aim of this study was to investigate the histopathological effects of ozone on bone graft materials and to ex- 
amine osteogenesis development induced by osteoconductive properties of these materials.

\section{Materials and Methods}

This study was carried out at the Dicle University Health Sciences and Application Center (DUSAM) with the approval of the Dicle University Experimental Animal Ethics Committee with the protocol dated 12.11.2013 and numbered 2013/55. In the study, 56 male Wistar rats weighing 280 - 300 grams were used and housed individually in suitable cages at temperatures of $22^{\circ} \mathrm{C} \pm 2^{\circ} \mathrm{C}$ and 12 hours of dark/12 hours of light conditions. The nutritional needs of the animals were met regularly with standard laboratory food and water. Four groups (14 rats per group) were arranged as below:

1) Control Group: Calvarial bone defect was created in 14 rats without any additional treatment and wound was sutured. Seven of the subjects were sacrificed at the end of the 4 th week, and the remaining 7 were sacrificed at the end of the 8th week.

2) Experimental Group: $8 \mathrm{~mm}$ calvarial bone defects were created in all rats and then treated with ozone. 7 of the subjects were sacrificed at the end of the 4 th week, and the remaining 7 were sacrificed at the end of the 8 th week.

3) Experimental Group: $8 \mathrm{~mm}$ calvarial bone defects were created in all rats and then alloplastic bone grafts were applied to the defect. 7 of rats were sacrificed at the end of the 4 th week and the remaining were sacrificed at the end of the 8th week.

4) Experimental Group: $8 \mathrm{~mm}$ calvarial bone defects were created in all rats and then alloplastic bone grafts + ozone treatment was applied to the defect. Seven of them were sacrificed at the end of the 4 th week, and the remaining were sacrificed at the end of the 8 th week.

\subsection{Surgical Operation}

The animals were anesthetized with intraperitoneally $3 \mathrm{mg} / \mathrm{kg}$ xylazine (Rompun 2\%; Bayer) and $90 \mathrm{mg} / \mathrm{kg}$ Ketamine $\mathrm{HCl}$ (Ketalar; Eczacibasi-Warner Lambert). Skin was incised to open frontal bone. A periosteal flap was removed with a thin elevator. Surgical sites were exposed with an incision through the skin and the periosteum at the midline of the calvaria. The periosteal flap was removed with a thin periosteal elevator and a specially designed trephine bur was created with a circular full-thickness bone defect with a diameter of $0.8 \mathrm{~cm}$ on the midline. After the graft was applied in our study, topical Ozone (Prozone W \& $\mathrm{H}$, Bürmoos, Austria) was applied for 12 seconds with a Coro-type applicator. Allografts are bone tissues of the same species as the recipient but derived from genetically distinct individuals. It is used as fresh frozen bone, frozen dried bone and demineralized bone matrix. Allograft material was used as demineralized bone matrix in our study.

Alloplastic material (Bio-Graft-HT) was placed in defect area in group 3 and group 4. Subcutaneous tissue was sealed with $6 / 0$ vicryl suture and skin was 
closed using 5/0 silk suture. Half of the experimental animals in all groups were sacrificed at the end of the 4th week and the remainder was sacrificed at the end of the 8th week by intraperitoneally overdose of sodium thiopentone. The skin on the calvarium was completely removed and the defect was taken out with bone forceps.

\subsection{Histopathological Protocol}

The bones from the calvarial region were fixed in $10 \%$ formalin solution. They were decalcified for 1 week in 10\% ethylene diamine tetra acetic acid (EDTA) solution. After washing, tissues were dehydrated through ascending alcohol series and cleared with xylene. After embedding them in paraffin, $4-6 \mu \mathrm{m}$ thick sections were taken with Leica ultramicrotome. Sections were stained with Masson Trichrome and Hematoxylin-Eosin and examined by light microscope.

\subsection{Statistical Analysis}

Statistics and analyzes were performed using the SPSS 22.0 for Windows computer package program, and the results were considered statistically significant for $p<0.05$. In the analysis of the data, Kruskall-Wallis and Mann-Whitney $\mathrm{U}$ non-parametric statistical tests were used in the intergroup comparisons depending on the variables and the results were given as mean and standard deviation values.

\section{Results}

\section{Histopathological Findings}

\section{1) 4th week findings}

a) Control Group: Figure 1(a) shows a significant increase was observed in osteoclast cells in defect area. Hemorrhage and dilatation in blood vessels and mononuclear cell infiltration were increased. Defect Group: In Figure 1( $\left.\mathrm{a}^{*}\right)$, in other section of the same group, an increase in fibrous tissue and collagen fibers, freely dispersed erythrocytes due to tearing in the vessel wall, intense mononuclear cell infiltration and rarely edema were observed.

b) Defect + Ozone treated Group: Sections showed dilatation was significantly increased in the veins. Comparing with the defect group, there was a decrease in fibrous tissue and osteoblastic activity in this group. In another section, the collagen fibers were bundled, the connective tissue were increased, new bone trabeculae were formed and the bone matrix began to become evident.

c) Defect + Graft Applied Group: Osteoblasts were clearly observable, connective tissue cells and fibrous structure around bone trabeculae were increased, graft resorption was decreased. A decrease in osteoblasts and cell infiltration was observed. In another section, bone trabeculae were more abundant around the veins and collagen fibers were observed in bundles. Decrease in connective tissue cells and dispersed erythrocytes were observed. A small number of osteocytes were found in bone trabeculae. 

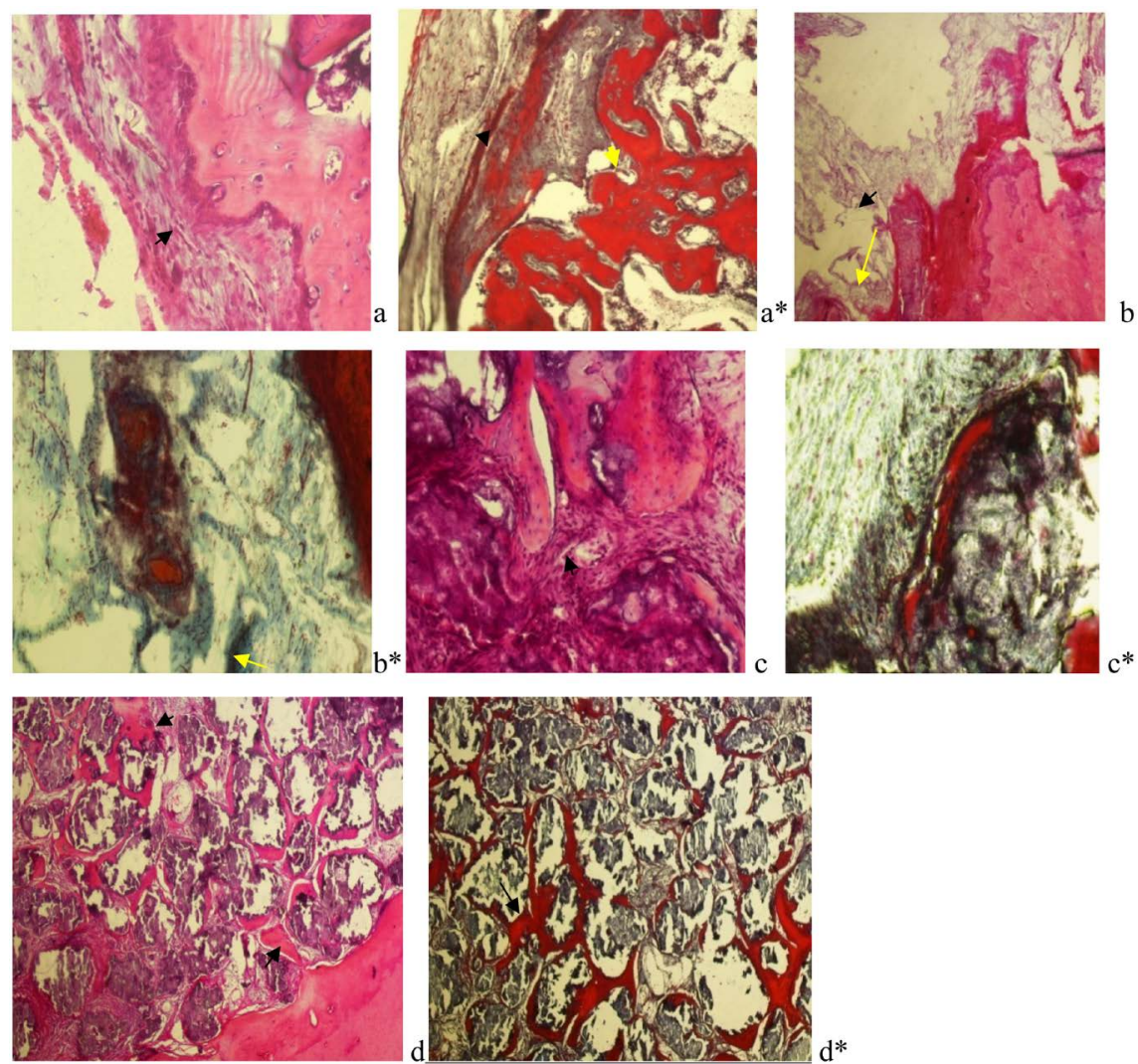

Figure 1. a: A significant increase was observed in osteoblast cells in defect area (arrow). $\mathrm{H}-\mathrm{E}$ staining Bar $50 \mu \mathrm{m} ; \mathrm{a}^{*}$ : An increase in fibrous tissue and collagen fibers (arrow), dilatation in blood vessels (yellow arrow) Trichrome Masson staining Bar $50 \mu \mathrm{m}$, b-İnflamatory cells in defect area (arrow) H-E staining Bar $50 \mu \mathrm{m}$; $\mathrm{b}^{*}$ : hemorrhage in blood vessels (yellow arrow) Trichrome Masson staining Bar $50 \mu \mathrm{m}$, c-osteoblast cells around bone trabecula (arrow), H-E staining Bar $50 \mu \mathrm{m}$; $\mathrm{c}^{\star}$ : intense inflammatory cells in graft area (yellow arrow) Trichrome Masson staining Bar $50 \mu \mathrm{m}$; d: An increase in osteoblastic activity and osteocyte cells (arrow), H-E staining Bar $50 \mu \mathrm{m} ; \mathrm{d}^{*}$ : Appearance of mature bone particles (arrow) Trichrome Masson staining Bar $50 \mu \mathrm{m}$.

d) Defect + Graft + Ozone Applied Group: In sections of this group, graft resorption began, bone trabeculae became evident due to an increase in dense connective tissue fibers and osteoblastic activity around the graft. Matrix development was increased and a small number of osteocytes in bone trabeculae were observed. In another section, dense connective tissue around the graft was enriched by especially collagen fibers, new bone formation in connective tissue began to increase and osteocyte cells with their lacunae became evident in new bone trabeculae.

For the $4^{\text {th }}$ week, cell infiltration was significantly different between the groups $(p<0.0001)$. When we examined osteoclastic activity of week 4 , there was a significant difference between the groups $(p=0.0001)$. There was a significant difference between the groups in osteoblastic activity of 4 th week $(p=0.253)$. There was a significant difference between the groups in terms of matrix formation ( $p=$ $0.0007)$, bone trabeculae $(p=0.0018$, vascular dilatation and hemorrhage ( $p=$ 
0.0005) and collagen fiber distribution $(p=0.0099)$ (Table 1).

\section{2) 8th week findings}

a) Control Group: In Figure 2(a), bone trabeculae were visible and osteoblasts were flattened and arranged in a single row around the trabeculae. While cell infiltration mostly gathered around the trabeculae, edema was seen in some areas. Vessels were dilated and apparently hemorrhagic. Figure $2\left(a^{*}\right)$ shows the collagen fibers were in bundled form, islets of bone trabeculae were seen, the osteoblastic activity was increased in the trabeculae and the matrix development

Table 1. Statistical evaluation of parameters according to 4 th week according to different groups.

(a)

\begin{tabular}{|c|c|c|c|c|c|c|}
\hline Parameter's & Groups & $\mathrm{n}$ & Mean & $\begin{array}{c}\text { Average } \\
\text { Rank }\end{array}$ & $\begin{array}{l}\text { Kruskal-Wallis } \\
\text { Test value }\end{array}$ & $\begin{array}{c}\text { Multiple } \\
\text { comparisons } \\
\text { for groups } \\
(p<0.05)\end{array}$ \\
\hline \multirow{5}{*}{$\begin{array}{c}\text { Cell } \\
\text { infiltration }\end{array}$} & (1) Control group & 7 & 3.71 & 22.00 & \multirow{4}{*}{$\begin{array}{c}20.3276 \\
p<0.0001\end{array}$} & (3) (4) \\
\hline & (2) Defect + Ozone & 7 & 3.57 & 21.00 & & (3) (4) \\
\hline & (3) Defect + Graft & 7 & 0.00 & 7.50 & & (1) (2) \\
\hline & (4) Defect + Graft + Ozone & 7 & 0.00 & 7.50 & & (1) (2) \\
\hline & (1) Control group & 7 & 0.00 & 4.00 & \multirow{4}{*}{$\begin{array}{c}20.1291 \\
p=0.0001\end{array}$} & (2) (3) (4) \\
\hline \multirow{3}{*}{$\begin{array}{l}\text { Osteoclastic } \\
\text { activity }\end{array}$} & (2) Defect + Ozone & 7 & 2.71 & 20.07 & & (1) (3) \\
\hline & (3) Defect + Graft & 7 & 1.71 & 12.43 & & (1) (2) (4) \\
\hline & (4) Defect + Graft + Ozone & 7 & 3.00 & 21.50 & & (1) (3) \\
\hline \multirow{5}{*}{$\begin{array}{l}\text { Osteoblastic } \\
\text { activity }\end{array}$} & (1) Control group & 7 & 1.57 & 18.93 & \multirow{4}{*}{$\begin{array}{c}2.9008 \\
p=0.2533\end{array}$} & \multirow{4}{*}{ ns } \\
\hline & (2) Defect + Ozone & 7 & 1.14 & 13.79 & & \\
\hline & (3) Defect + Graft & 7 & 1.00 & 11.93 & & \\
\hline & (4) Defect + Graft + Ozone & 7 & 1.14 & 13.36 & & \\
\hline & (1) Control group & 7 & 3.00 & 20.50 & \multirow{4}{*}{$\begin{array}{c}15.5120 \\
p=0.0007\end{array}$} & (2) (4) \\
\hline \multirow{3}{*}{$\begin{array}{l}\text { Matrix } \\
\text { formation }\end{array}$} & (2) Defect + Ozone & 7 & 2.00 & 11.71 & & (1) (3) (4) \\
\hline & (3) Defect + Graft & 7 & 3.00 & 20.00 & & (2) (4) \\
\hline & (4) Defect + Graft + Ozone & 7 & 1.29 & 5.79 & & (1) (2) (3) \\
\hline \multirow{4}{*}{$\begin{array}{c}\text { Bone } \\
\text { trabeculae }\end{array}$} & (1) Control group & 7 & 2.14 & 13.36 & \multirow{4}{*}{$\begin{array}{c}10.6784 \\
p=0.0018\end{array}$} & (4) \\
\hline & (2) Defect + Ozone & 7 & 1.71 & 8.64 & & (4) \\
\hline & (3) Defect + Graft & 7 & 2.14 & 13.36 & & (4) \\
\hline & (4) Defect + Graft + Ozone & 7 & 2.86 & 22.64 & & (1) (2) (3) \\
\hline \multirow{4}{*}{$\begin{array}{c}\text { Vessel } \\
\text { dilatation and } \\
\text { hemorrhage }\end{array}$} & (1) Control group & 7 & 2.14 & 16.29 & \multirow{4}{*}{$\begin{array}{c}15.6492 \\
p=0.0005\end{array}$} & (3) \\
\hline & (2) Defect + Ozone & 7 & 2.29 & 17.36 & & (3) \\
\hline & (3) Defect + Graft & 7 & 0.29 & 4.14 & & (1) (2) (4) \\
\hline & (4) Defect + Graft + Ozone & 7 & 2.57 & 20.21 & & (3) \\
\hline \multirow{4}{*}{$\begin{array}{l}\text { Collagen } \\
\text { fibers }\end{array}$} & (1) Control group & 7 & 2.71 & 17.79 & \multirow{4}{*}{$\begin{array}{c}9.0654 \\
p=0.0099\end{array}$} & (3) \\
\hline & (2) Defect + Ozone & 7 & 2.71 & 17.79 & & (3) \\
\hline & (3) Defect + Graft & 7 & 1.71 & 6.50 & & (1) (2) (4) \\
\hline & (4) Defect + Graft + Ozone & 7 & 2.57 & 15.93 & & (3) \\
\hline
\end{tabular}

ns: non-significant; $p>005$. 
(b)
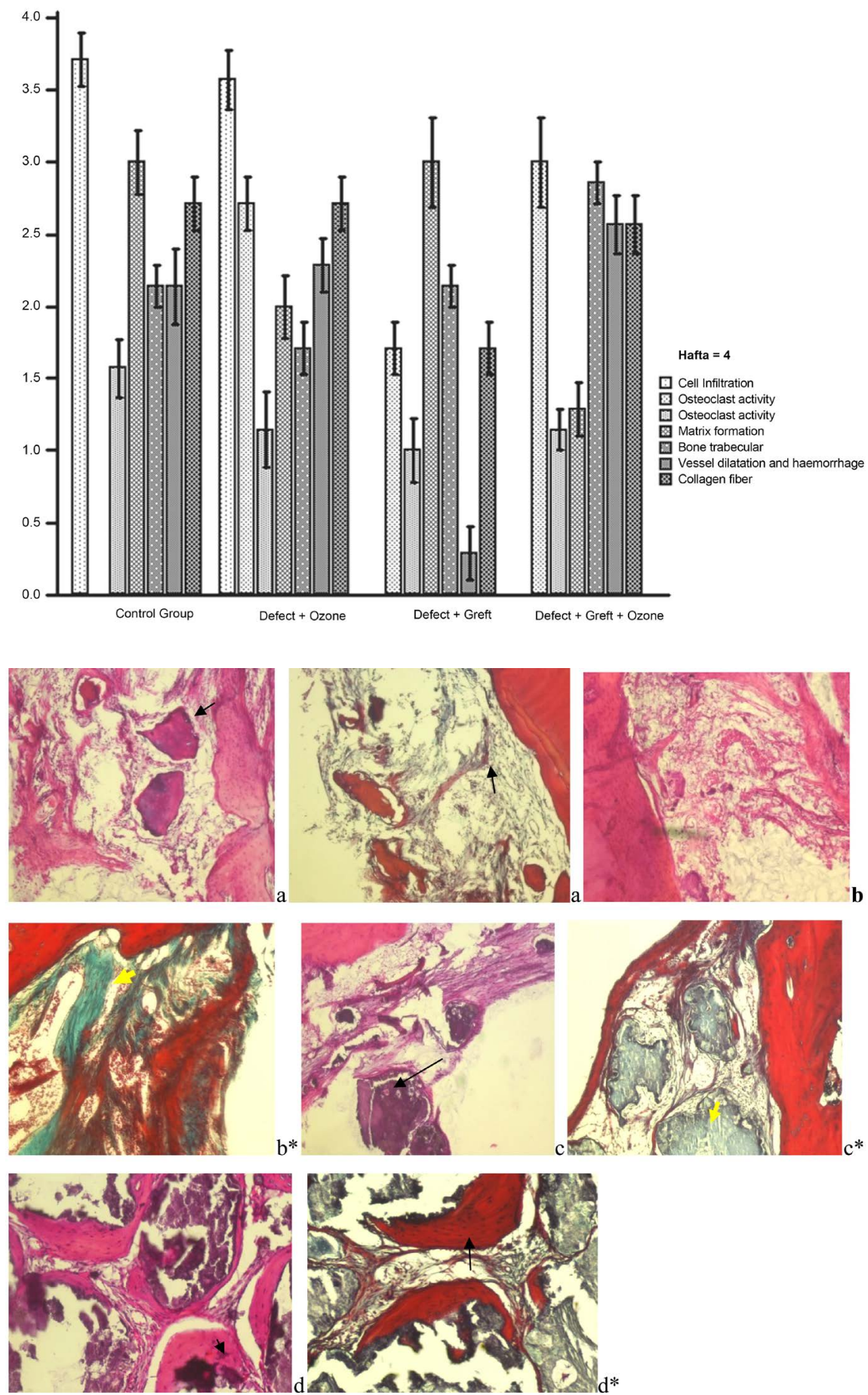

Figure 2. a: bone trabeculae in defect area (arrow). H-E staining Bar $50 \mu \mathrm{m} ; \mathrm{a}^{\star}$ : An increase in fibrous tissue and collagen fibers(arrow), Trichrome Masson staining Bar 50 $\mu \mathrm{m}$; b: Inflammatory cells in defect area (arrow) H-E staining Bar $50 \mu \mathrm{m}$; $\mathrm{b}^{\star}$ : increase of collagen fibers in defect area (yellow arrow) Trichrome Masson staining Bar $50 \mu \mathrm{m}$; $\mathrm{c}$ Appearance of mature bone trabecula (arrow), H-E staining Bar $50 \mu \mathrm{m} ; \mathrm{c}^{*}$ : Enlargement bone trabecula in graft area (yellow arrow) Trichrome Masson staining Bar $50 \mu \mathrm{m}$; $\mathrm{d}$ : An increase in bone trabeculae and osteocyte cells (arrow), H-E staining Bar $50 \mu \mathrm{m}$; $\mathrm{d}^{*}$ : Appearance of mature bone particles (arrow) Trichrome Masson staining Bar $50 \mu \mathrm{m}$. 
started. Extracellular matrix of connective tissue was increased. Form of fully developed mature bone cells were not observed in this group.

b) Defect + Ozone Applied Group: Islets of inflammatory cells; hemorrhage and dilatation in vessels of the defect areacan be seen in Figure 2(b). Throughout new bone formation, matrix development was apparently begun. There were bone trabeculae in some areas. Figure $2\left(b^{*}\right)$ shows thickening in collagen fibers, intense hemorrhagic areas in defect region, enlargement of the bone matrix and new bone trabeculae formation were observed.

c) Defect + Graft Group: The histological examination of this group showed new bone trabeculae with increased connective tissue around the graft sites. As cell infiltration continued, freely distributed erythrocytes were found in connective tissue. Osteoblast cells were clearly observed around the bone trabeculae as seen in Figure 2(c). Graft resorption was dispersed and graft areas began to diminish gradually. In Figure 2( $\left.c^{*}\right)$, collagen fibers were tightly gathered around graft areas and made resorbed grafts reduce. Inflammatory cells spread diffusely between graft areas, and new bone particles began to become apparent in the periphery of graft.

d) Defect + Graft + Ozone Applied Group: Figure 2(d) shows that the new bone trabeculae around the graft areas began to turn into mature flat bone and osteocytes cells were abundant due to increased osteoblastic activity. Cell infiltration was gradually reduced and mature bone trabeculae were formed in the site of resorbed graft. In Figure $2\left(d^{*}\right)$, revealed shrinkage in the resorbed graft sites, the structures of mature bone particles became evident and fibrillary development in the connective tissue accelerated and wrapped around the bonetrabeculae.

There was a significant difference between the groups when the weekly cell infiltration $(p=0.0014)$, osteoclastic $(p=0.0004)$ and osteoblastic $(p=0.0055)$ activities were examined. Matrix formation at 8 weeks $(p=0.0001)$, Bone trabeculae $(p=0.0002)$ There was a significant difference between the groups when vascular dilatation and hemorrhage $(p<0.0001)$ and collagen fiber distribution $(p<0.0001)$ (Table 2 and Table 3$)$.

Table 2. Statistical evaluation of parameters according to 8th week according to different groups.

(a)

\begin{tabular}{|c|c|c|c|c|c|c|}
\hline Parameter & Groups & $\mathrm{n}$ & Mean & $\begin{array}{l}\text { Average } \\
\text { Rank }\end{array}$ & $\begin{array}{c}\text { Kruskal-Wallis } \\
\text { Test value }\end{array}$ & $\begin{array}{c}\text { Multiple } \\
\text { comparisons } \\
\text { for groups } \\
(p<005)\end{array}$ \\
\hline \multirow{4}{*}{$\begin{array}{c}\text { Cell } \\
\text { infiltration }\end{array}$} & (1) Control & 7 & 3.29 & 22.50 & \multirow{4}{*}{$\begin{array}{c}13.3723 \\
p=0.0014\end{array}$} & (3) (4) \\
\hline & (2) Defect + Ozone & 7 & 2.86 & 17.21 & & (3) (4) \\
\hline & (3) Defect + Graft & 7 & 2.86 & 8.64 & & (1) (2) \\
\hline & (4) Defect + Graft + Ozone & 7 & 1.14 & 9.64 & & (1) (2) \\
\hline \multirow{2}{*}{$\begin{array}{l}\text { Osteoclastic } \\
\text { activity }\end{array}$} & (1) Control & 7 & 2.71 & 6.57 & \multirow{2}{*}{$\begin{array}{c}14.5683 \\
p=0.0004\end{array}$} & (2) (4) \\
\hline & (2) Defect + Ozone & 7 & 1.29 & 21.57 & & (1) (3) \\
\hline
\end{tabular}




\section{Continued}

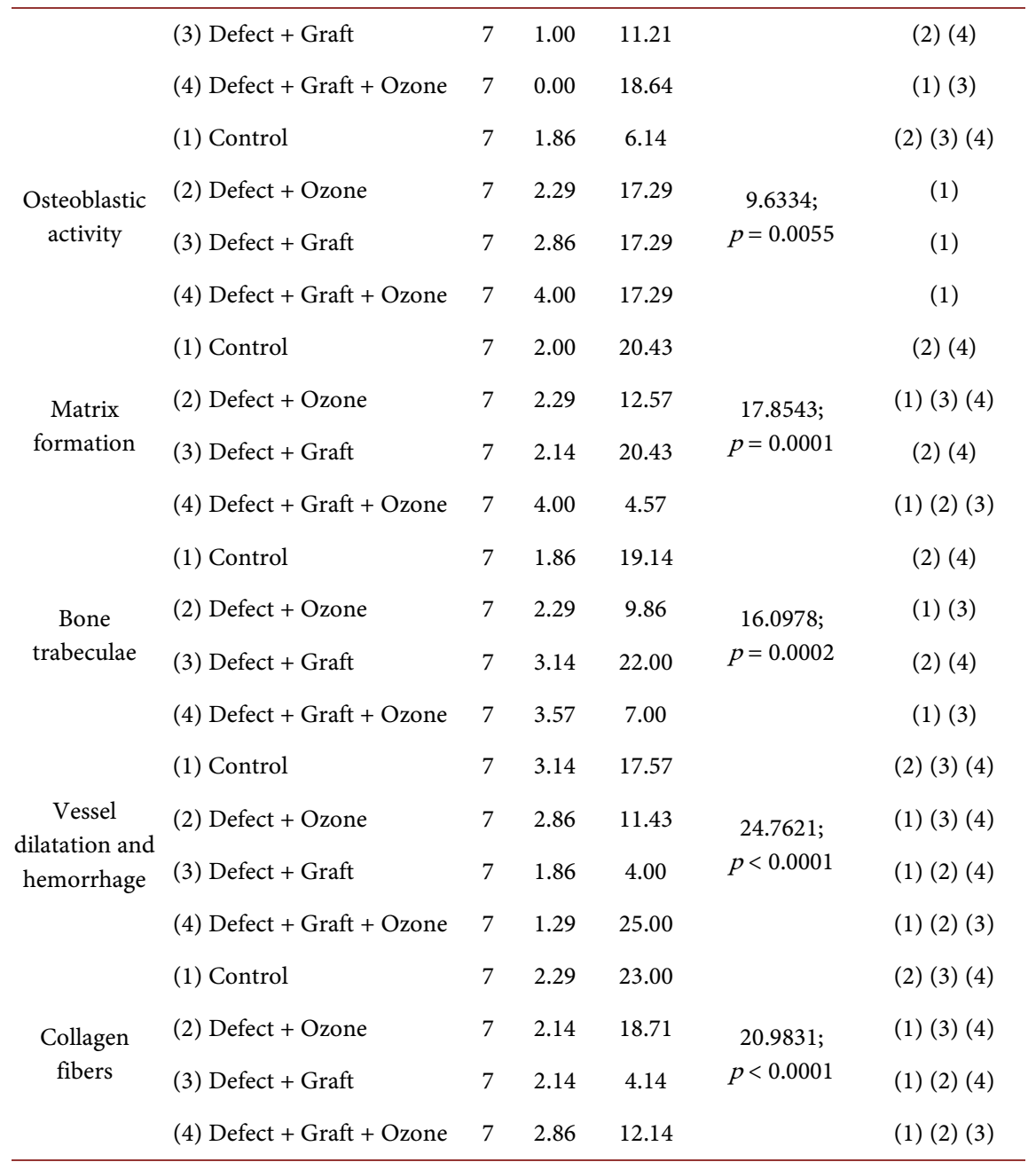

ns: non-significant; $p>0.05$.

(b)

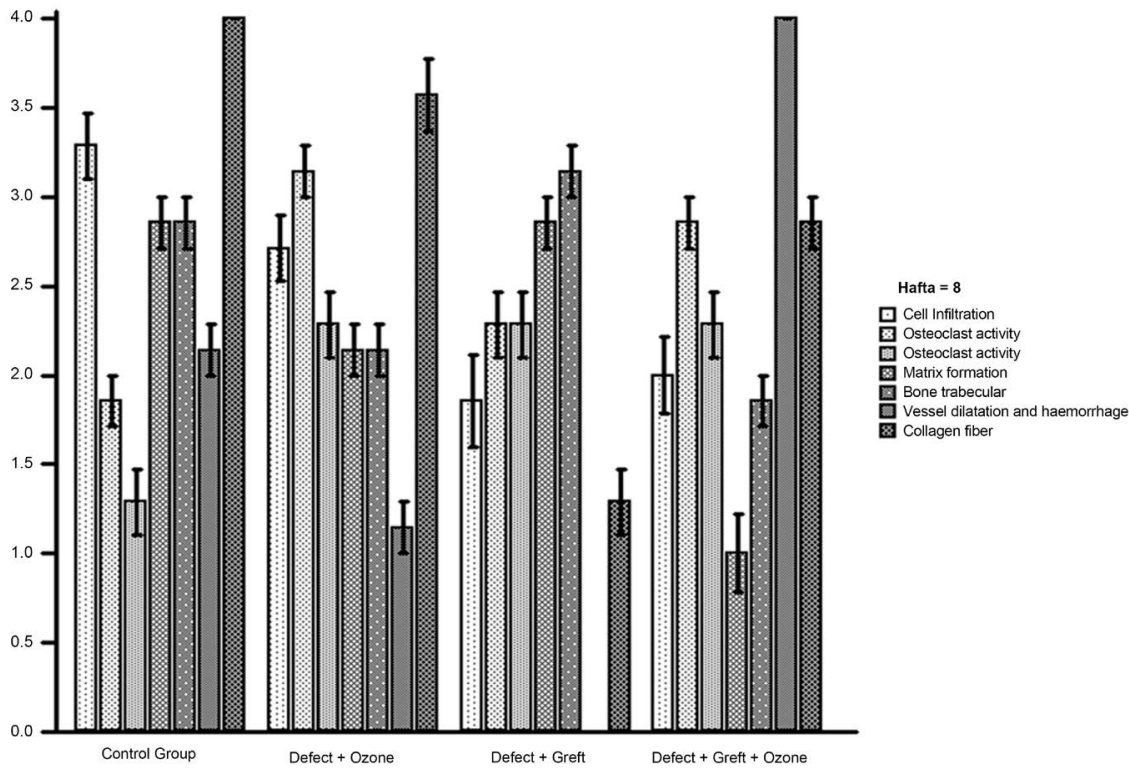


N. Laçin et al.

Table 3. Statistical evaluation of parameters according to 4 th and 8th week according to different groups.

\begin{tabular}{|c|c|c|c|c|c|}
\hline Parameters & Groups & Weeks & Mean & Mean Rank & $p$ \\
\hline \multirow{8}{*}{ Cell infiltration } & \multirow{2}{*}{ Control group } & 4 & 3.71 & 1.71 & \multirow{2}{*}{0.180} \\
\hline & & 8 & 3.29 & 1.29 & \\
\hline & \multirow{2}{*}{ Defect + Ozone } & 4 & 3.00 & 1.57 & \multirow{2}{*}{0.655} \\
\hline & & 8 & 2.86 & 1.43 & \\
\hline & \multirow{2}{*}{ Defect + Graft } & 4 & 3.00 & 1.57 & \multirow{2}{*}{0.655} \\
\hline & & 8 & 2.86 & 1.43 & \\
\hline & \multirow{2}{*}{ Defect + Graft + Ozone } & 4 & 2.29 & 2.00 & \multirow{2}{*}{0.008} \\
\hline & & 8 & 1.14 & 1.00 & \\
\hline \multirow{8}{*}{ Osteoclastic activity } & \multirow{2}{*}{ Control group } & 4 & 3.57 & 1.93 & \multirow{2}{*}{0.014} \\
\hline & & 8 & 2.71 & 1.07 & \\
\hline & \multirow{2}{*}{ Defect + Ozone } & 4 & 1.57 & 1.64 & \multirow{2}{*}{0.317} \\
\hline & & 8 & 1.29 & 1.36 & \\
\hline & \multirow[b]{2}{*}{ Defect + Graft } & 4 & 1.29 & 1.57 & \multirow[b]{2}{*}{0.317} \\
\hline & & 8 & 1.00 & 1.43 & \\
\hline & \multirow{2}{*}{ Defect + Graft + Ozone } & 4 & 0.29 & 1.64 & \multirow{2}{*}{0.157} \\
\hline & & 8 & 0.00 & 1.36 & \\
\hline \multirow{8}{*}{ Osteoblastic activity } & \multirow{2}{*}{ Control group } & 4 & 0.00 & 1.00 & \multirow{2}{*}{0.008} \\
\hline & & 8 & 1.86 & 2.00 & \\
\hline & \multirow{2}{*}{ Defect + Ozone } & 4 & 1.14 & 1.07 & \multirow{2}{*}{0.014} \\
\hline & & 8 & 2.29 & 1.93 & \\
\hline & \multirow{2}{*}{ Defect + Graft } & 4 & 2.14 & 1.14 & \multirow{2}{*}{0.025} \\
\hline & & 8 & 2.86 & 1.86 & \\
\hline & \multirow{2}{*}{ Defect + Graft + Ozone } & 4 & 2.57 & 1.00 & \\
\hline & & 8 & 4.00 & 2.00 & 0.008 \\
\hline & Control group & 4 & .00 & 1.00 & 0.008 \\
\hline & & 8 & 2.00 & 2.00 & \\
\hline & Defoct + Orane & 4 & 1.00 & 1.00 & 0000 \\
\hline & Detect o OLOHE & 8 & 2.29 & 2.00 & 0.000 \\
\hline 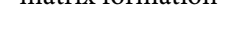 & & 4 & 1.71 & 1.29 & \\
\hline & 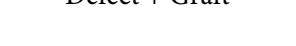 & 8 & 2.14 & 1.71 & 0.000 \\
\hline & & 4 & 2.71 & 1.00 & 0000 \\
\hline & & 8 & 4.00 & 2.00 & 0.000 \\
\hline & Control aroun & 4 & 0.00 & 1.00 & 0008 \\
\hline & Corition givup & 8 & 1.86 & 2.00 & 0.000 \\
\hline & Defect + Orone & 4 & 1.14 & 1.07 & \\
\hline & Delect + Ozone & 8 & 2.29 & 1.93 & 0.014 \\
\hline Doile tiavecturat & & 4 & 2.14 & 1.07 & \\
\hline & Deiect T Gidal & 8 & 3.14 & 1.93 & 0.014 \\
\hline & Defect + Graft + Orone & 4 & 2.71 & 1.14 & 0025 \\
\hline & Detect + Grall + OzOne & 8 & 3.57 & 1.86 & 0.025 \\
\hline
\end{tabular}




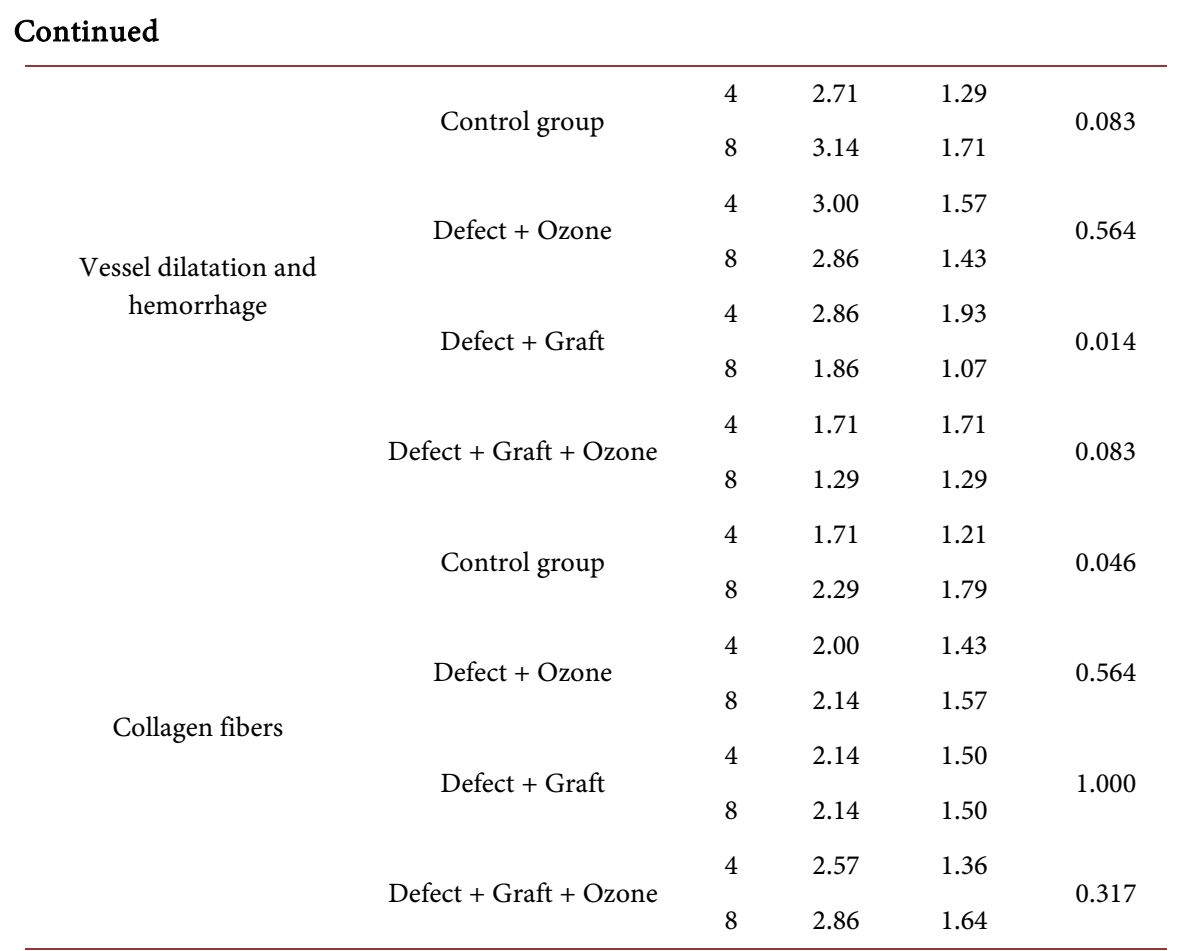

When compared histologically at 4 and 8 weeks; colloid fiber growth, matrix formation and new bone formation were less than 4 weeks to 8 weeks. Vessel dilatation and hemorrhage increased cell infiltration over 4 weeks to 8 weeks, osteoblastic activity significantly increased bone trabecular formation at 8 weeks. In bone formation, post-defect graft application was evident at 8 weeks, ozone application increased bone formation as an inducing agent.

\section{Discussion}

Nagayoshi et al. [15] found that no microorganisms remained in the plaque after ozonized water treatment on the dental plaque. In oral surgery, ozonized water is used to provide hemostasis, to increase local oxygen delivery to the site, and to inhibit bacterial proliferation [13]. Ozonized water has also been proposed to use as a prophylactic agent against infection after osteotomy during oral surgery. Following the high dose of radiotherapy treatment, ozone treatment has been shown to be effective in improvement of wound healing [16]. After radiotherapy in maxilla or mandible, in areas where especially oxygen is greatly reduced, spongy medullary regions become inadequately vascularized due to deterioration of vascularity, resulting in aseptic osteonecrosis [16]. In surgical procedures such as tooth extraction or implant application, the healing of the damaged region takes longer than the healing of the healthy bone [16] [17]. Schmitz and his colleagues studied in 3, 4, 5 and $8 \mathrm{~mm}$ defects and suggest that an $8 \mathrm{~mm}$ defect is an ideal defect [18]. In our study, $8 \mathrm{~mm}$ defects were created. Different bone graft materials have been used for bone regeneration, closure of osteotomy openings, and alveolar augmentation in oral and maxillofacial surgeons [19] 
[20]. Natural coral-derived grafts, synthetic bone graft materials, are used in alveolar crest elevation, intra-bone defects, material loss fractures, facial bone defects, orthognathic surgery, and maxillary sinus ground [20] [21] [22]. In our study, an alloplastic graft material consisting of a combination of $350-500$ $\mu \mathrm{m}$-diameter porous biphasic hydroxyapatite granules and $\beta$-tricalcium phosphate granules was used. Agrillo et al. have studied the effects of ozone on wound healing after tooth extraction in 15 patients using bisphosphonates. Topical ozone gas with $\beta$-lactam antibiotics were applied to all patients 1 week before and after tooth extraction. Clinical and radiological follow-ups of patients showed complete healing in the extraction socket [23]. Kazancioğlu et al. formed a $5 \mathrm{~mm}$ diameter bone defect in 30 Wistar rats. They created defects and filled them with biphasic calcium phosphate grafts. They categorized rats into three groups and histomorphometrically compared the effect of laser and ozone on new bone formation. Kazancioğlu et al. observed significant bone formation in both groups compared to the control group [24]. Özdemir et al. have studied the effect of ozone treatment on autogenous bone graft healing in calvarial defects. Histological results of this study revealed that there was an increase in osteoblastic activity and significant difference in bone formation in ozone treated group [25]. In the histopathological examination of week 4 of our study, a significant increase in osteoblastic activity was observed in all compared to the control group. Week 8 results showed significant increase in osteoblastic activity in graft + ozone group compared to all other groups. More bone trabecular formation was observed in the groups treated with grafts and grafts + ozone compared to the group treated with only ozone. 4th week histological evaluations on matrix formation showed a significant increase in all groups compared with the control group at the end of. Statistically speaking on histological results, 4-week ozone treatment is less effective than 8-week ozone treatment and additionally 8-week treatment is more effective and significant than 4 -week-treatment in total. In our study, there was a significant difference between the groups treated with $s$ graft + ozone and the other groups in terms of cell infiltration in the groups sacrificed at 8 weeks. There was no significant difference in comparison between the other groups. Erdemci et al. studied on the effect of systemic ozone on alveolar bone healing. A total of 112 Wistar rats were used, and they were sacrificed on days 14 and 28. They reported systemic ozone treatment significantly improved alveolar bone healing after extraction [26]. In their study, unlike the half of the rats at the end of 4 week, the remaining half was sacrificed at the end of the 8th week. Each group was divided into 2 subgroups. A critical size bone defect of $8 \mathrm{~mm}$ in diameter was formed in the calvarium of all rats. Topical ozone was applied to the ozone treated groups for $12 \mathrm{sec}$.

In our study, it was determined that ozone application accelerated bone healing in parallel with this study. It was observed that topical ozone administration at week 4 failed to exert only osteoblastic activity on graft application. However, ozone and graft combination may be beneficial. When the bone trabeculae were 
taken to evaluate the 8th week groups, a statistically significant increase was observed only in the graft and graft + ozone treated groups compared to the control group When the 4- and 8-week findings were evaluated; the best result for new bone formation was obtained from the graft + ozone treated group. It is thought that ozone application increases the hemostasis in the region and induces angiogenesis, increases cell proliferation by preventing infiltration. It also promotes osteoblastic activity and matrix formation and has a positive effect on estrogen

\section{References}

[1] Kabaca, G. (2007) The Effects of Selenium on Bone Healing in Diabetic Rats. Doctorate Thesis, Istanbul University Health Sciences Institute, Istanbul.

[2] Comproresi, E.M. (1999) Hyperbaric Oxygen Therapy: A Committee Report. Undersea and Hyperbaric Medical Society, North Palm Beach.

[3] Beumer, J., Curtis, T.A. and Firteli, D.A. (1979) Maxillofacial Rehabilitation. The CV Mosby Company, St. Louis.

[4] Kökden, A. and Türker, M. (1999) Bone Grafts and Biomaterials Used in Oral and Maxillofacial Surgery. Cumhuriyet University Dentistry Faculty Magazine, 2, 134-140.

[5] Cute, S.Y. (2005) Investigation of the Effects of Hyperbaric Oxygen Application on Ossification of Different Types of Artificial Welded Graft Materials Placed in Experimental Bone Defects. Doctorate Thesis, Istanbul University Health Sciences Institute, Istanbul.

[6] Garg, A.K. (1999) Grafting Materials in Repair and Restoration. In: Lynch, S.E., Genco, R.J. and Marx, R.E., Eds., Tissue Engineering. Applications in Maxillofacial Surgery and Periodontics, Quintessence Publishing, Illinois, 83-102.

[7] Tuskan, C. and Yaltırık, M. (2002) Biomaterials Used in Oral and Maxillofacial Surgery. IU Faculty of Dentistry Istanbul Part I, II.

[8] Sanan, A. and Haines, S.J. (1997) Repearing Holes in the Head: A History of Cranioplasty. Neurosurgery, 40, 588-603.

[9] Bocci, V. (2004) Ozone as Janus: This Controversial Gas Can Be Either Toxic or Medically Useful. Mediators of Inflammation, 13, 3-11.

https://doi.org/10.1080/0962935062000197083

[10] Ozone, B.V. (2005) A New Medical Drug. Springer, Dordrecht, 1-295.

[11] Atalay, B. (2007) Histopathologic Investigation of Bone Healing Effect of Graft Materials Placed in Bone Defects in Experimental Iron Anxiety Anemia Rats. PhD Thesis, Istanbul University Health Sciences Institute, Istanbul.

[12] Brazzelli, M., McKenzie, L., Fielding, S., Fraser, C., Clarkson, J., Kilonzo, M. and Waugh, N. (2006) Systematic Review of the Effectiveness and Cost-Effectiveness of HealOzone for the Treatment of Occlusal Pit/Fissure Caries and Root Caries. Health Technology Assessment, 10, iii-iv, ix-80.

[13] Baysan, A. and Beighton, D. (2007) Assessment of the Ozone-Mediated Killing of Bacteria in Infected Dentine Associated with Non-Cavitated Occlusal Carious Lesions. Caries Research, 41, 337-341. https://doi.org/10.1159/000104790

[14] Baysan, A. and Lynch, E. (2006) The Use of Ozone in Dentistry and Medicine. Part 2. Primary Dental Care, 13, 37-41. https://doi.org/10.1308/135576106775193897 
[15] Nagayoshi, M., Fukuizumi, T., Kitamura, C., Yano, J., Terashita, M. and Nishihara, T. (2004) Efficacy of Ozone on Survival and Permeability of Oral Microorganisms. Oral Microbiology and Immunology, 19, 240-246. https://doi.org/10.1111/j.1399-302X.2004.00146.x

[16] Viebahn-Haensler, R. (2005) Application Forms and Uses of Ozone; Envy of Ozone Use. Medical Ozone Oxygen Association, 53-66.

[17] Harrison, J.S., Stratemann, S. and Redding, S.W. (2003) Dental Implants for Patients who Have Had Radiation Treatment for Head and Neck Cancer. Special Care in Dentistry, 23, 223-229. https://doi.org/10.1111/j.1754-4505.2003.tb00316.x

[18] Schmitz, J.P., Schwartz, Z., Hollinger, J.O. and Boyan, B.D. (1990) Characterization of Rat Calvarial Nonunion Defects. Acta Anatomica, 138, 185-192. https://doi.org/10.1159/000146937

[19] Beirne, O.R. (1986) Comparison of Complications after Bone Removal from Lateral and Medial Plates of Anterior Ileum for Mandibular Augmentation. International Journal of Oral and Maxillofacial Surgery, 15, 269-272. https://doi.org/10.1016/S0300-9785(86)80084-9

[20] Byrd, H.S., Hobar, P.C. and Shewmake, K. (1993) Augmentation of the Craniofacial Skeleton with Porous Hydroxyapatite Granules. Plastic and Reconstructive Surgery, 91, 15-22. https://doi.org/10.1097/00006534-199301000-00003

[21] Corsair, A. (1990) A Clinical Evaluation of Resorbable Hydroxyapatite Fort the Repair of Human Intra-Osseous Defects. The Journal of Oral Implantology, 16, 125-128.

[22] Page, D.G. and Laksin, D.M. (1987) Tissue Response at the Bone-Implant Interface in a HA Augmentation Mandibular Ridge. Journal of Oral and Maxillofacial Surgery, 45, 356-358. https://doi.org/10.1016/0278-2391(87)90360-0

[23] Agrillo, A., Sassano, P., Rinna, C., et al. (2007) Ozone Therapy in Extractive Surgery on Patients Treated with Bisphosphonates. Journal of Craniofacial Surgery, 18, 1068-1070. https://doi.org/10.1097/SCS.0b013e3181572609

[24] Kazancioglu, H.O., Ezirganli, S. and Aydin, M.S. (2013) Effects of Laser and Ozone Therapies on Bone Healing in the Calvarial Defects. Journal of Craniofacial Surgery, 24, 2141-2146. https://doi.org/10.1097/SCS.0b013e3182a244ae

[25] Ozdemir, H., Toker, H., Balci, H., et al. (2013) Effect of Ozone Therapy on Autogenous Bone Graft Healing in Calvarial Defects: A Histologic and Histometric Study in Rats. Journal of Periodontal Research, 48, 722-726. https://doi.org/10.1111/jre.12060

[26] Erdemci, F., Gunaydin, Y., Sencimen, M., et al. (2014) Histomorphometric Evaluation of the Effect of Systemic and Topical Ozone on Alveolar Bone Healing Following Tooth Extraction in Rats. International Journal of Oral and Maxillofacial Surgery, 43, 777-783. https://doi.org/10.1016/j.ijom.2013.12.007 